\title{
Self-Regeneration Pd-Perovskite Anode for SOFC
}

\author{
Hiroshi FukUnAGA ${ }^{1}$, Yoshimi NumAZAwA ${ }^{1}$, \\ Akinori FUEOKA ${ }^{1}$, Chikao ARAI ${ }^{1}$, \\ Toru TAKATSUKA ${ }^{1}$ and Koichi YAMADA ${ }^{2}$ \\ ${ }^{1}$ Department of Fine Materials Engineering, Shinshu University, \\ 3-15-1, Tokida, Ueda-shi, Nagano 386-8567, Japan \\ ${ }^{2}$ The University of Tokyo, 7-3-1, Hongo, Bunkyo-ku, \\ Tokyo 113-8654, Japan
}

Keywords: SOFC, Perovskite Anode, Pd Doping, Dry Methane, Metal Free

\begin{abstract}
A Pd doped perovskite $\mathrm{La}_{0.85} \mathrm{Sr}_{0.15} \mathrm{Cr}_{0.9} \mathrm{Ni}_{0.05} \mathrm{Pd}_{0.05} \mathrm{O}_{3}(\mathrm{LSCNP})$ was investigated as a candidate for a metalfree anode material of solid oxide fuel cell in comparison with $\mathrm{La}_{0.85} \mathrm{Sr}_{0.15} \mathrm{Cr}_{0.9} \mathrm{Ni}_{0.1} \mathrm{O}_{3}$ (LSCN). The performance of anodes of LSCNP and LSCN with and without mixing Sm doped Ceria (SDC) was measured using $\mathrm{H}_{2}$ and dry- $\mathrm{CH}_{4}$ as fuel. The maximum current density of the cell in $\mathrm{H}_{2}$ increased approximately twofold by the doping of Pd for the anode with or without SDC. The rate of the anodic reaction in $\mathrm{H}_{2}$ was enhanced mainly by the catalytic activity of LSCNP and additionally by SDC. When dry-CH $\mathrm{CH}_{4}$ used $^{-}$ as the fuel, the cell with LSCNP-SDC anode was the only cell which was able to perform power generation. Both the doping of Pd to the perovskite and the mixing of SDC contributed to the ability to operate SOFC in dry $\mathrm{CH}_{4}$. The anode reaction did not occur when SDC was not in the anode, indicating that the supply of oxide ion was the rate determining step. Pd, which is considered to deposit from LSCNP in reducing atmosphere, seemed to be the reaction site of the electrochemical methane oxidation since the reaction rate was low for LSCN-SDC. Although slight indication of carbon deposition was observed, Pd doped perovskite would be a good candidate for metal-free SOFC anode.
\end{abstract}

\section{Introduction}

Solid oxide fuel cell (SOFC) is recently attracting much attention for its high electrical efficiency and low environmental impact. The operating temperature of SOFC is as high as $700-1000^{\circ} \mathrm{C}$. This high temperature enables SOFC to be operated by hydrocarbonbased fuel without using external fuel reformer. However, the high temperature would cause agglomeration of the particle and degradation of the electrode performance. Therefore, it is necessary to develop electrode material which would maintain stable microstructure at high temperature. The state of the art anode of SOFC is a cermet anode which is composed of $\mathrm{Ni}$ and yttria stabilized zirconia (YSZ). However, Ni tends to sinter easily at high temperature. Moreover, the volume of the particle changes when the $\mathrm{Ni}$ is oxidized and reduced, which would cause the cell to crack. Recently, $\mathrm{Ni}$-free electrode is being studied to avoid these problems. Novel anode materials based on perovskite such as lanthanum chromite (Sfeir et al., 2001) and strontium titanate (Pudmich et al., 2000) has been de-

Received on May 16, 2007; accepted on September 7, 2007. Correspondence concerning this article should be addressed to H. Fukunaga (E-mail address: fuku@shinshu-u.ac.jp).

Presented at International Symposium on Innovative Materials for Processes in Energy Systems, IMPRES, Kyoto, October, 2007. veloped. In the meantime, a Pd doped perovskite has been studied as a self-regeneration catalyst for automotive emissions control. It has been reported (Nishihata et al., 2002) that $\mathrm{LaFe}_{0.57} \mathrm{Co}_{0.38} \mathrm{Pd}_{0.05} \mathrm{O}_{3}$ had maintained its high dispersion of precious metals by the movement of Pd inside and outside the perovskite lattice due to the structural responses to the redox fluctuations in the exhaust gas composition with gasoline engine. In the present paper, $\mathrm{Pd}$-doped perovskite $\mathrm{La}_{1-X} \mathrm{Sr}_{X} \mathrm{Cr}_{1-Y-Z} \mathrm{Ni}_{Y} \mathrm{Pd}_{Z} \mathrm{O}_{3}$ (LSCNP) has been studied as a candidate for SOFC anode.

\section{Experimental}

\subsection{Powder Preparation}

$\mathrm{La}_{0.85} \mathrm{Sr}_{0.15} \mathrm{Cr}_{0.9} \mathrm{Ni}_{0.05} \mathrm{Pd}_{0.05} \mathrm{O}_{3} \quad$ (LSCNP) and $\mathrm{La}_{0.85} \mathrm{Sr}_{0.15} \mathrm{Cr}_{0.9} \mathrm{Ni}_{0.1} \mathrm{O}_{3}$ (LSCN) has been prepared using citric acid complex method. Nitrates of each metal, $\mathrm{La}\left(\mathrm{NO}_{3}\right)_{3} \cdot 6 \mathrm{H}_{2} \mathrm{O}(99.99 \%$, Kanto Chemical Co., Inc.), $\mathrm{Sr}\left(\mathrm{NO}_{3}\right)_{2}(99.5 \%$, Kanto Chemical Co., Inc.), $\mathrm{Cr}\left(\mathrm{NO}_{3}\right)_{3} \cdot 9 \mathrm{H}_{2} \mathrm{O}(99.99 \%$, Kanto Chemical Co., Inc.), $\mathrm{Ni}\left(\mathrm{NO}_{3}\right)_{2} \cdot 6 \mathrm{H}_{2} \mathrm{O}(99.99 \%$, Kanto Chemical Co., Inc.), and $\mathrm{Pd}\left(\mathrm{NO}_{3}\right)_{2}(99.9 \%$, Kanto Chemical Co., Inc.) were dissolved in distilled water. Then an aqueous solution of citric acid solution was added dropwise to the mixture which was stirred and heated at $70^{\circ} \mathrm{C}$ on a hot plate with magnetic stirrer. The resulting solution was evaporated by heating on a hot plate until a resin was formed. 


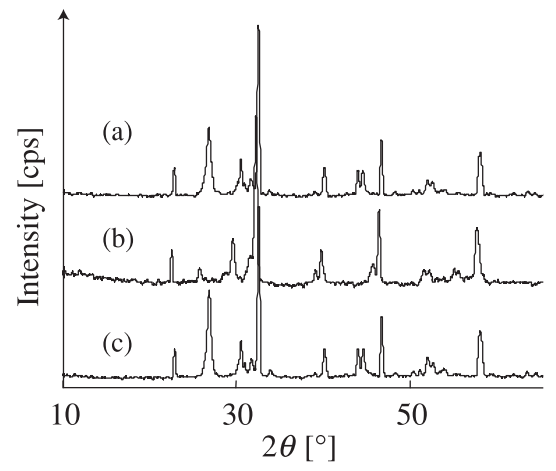

Fig. 1 XRD spectra of LSCNP: (a) as prepared; (b) after reduction; (c) after re-oxidation treatment

The obtained resin was calcined with an electric furnace (KM-160, ADVANTEC MFS, INC.) at $200^{\circ} \mathrm{C}$ for $2 \mathrm{~h}, 500^{\circ} \mathrm{C}$ for $2 \mathrm{~h}$, and $1000^{\circ} \mathrm{C}$ for $18 \mathrm{~h}$. The powder was ground and mixed by an agate mortar and a pestle between each calcination process. The obtained oxide was characterized by X-ray powder diffraction.

\subsection{Reduction}

The powder of LSCNP was heated at $800^{\circ} \mathrm{C}$ in a reducing atmosphere of $10 \%$ hydrogen and $90 \%$ nitrogen. The powder before and after the reduction was observed by XRD to confirm the existence of particle deposition.

\subsection{Cell Preparation}

SOFC cell was prepared using Sm doped Ceria (SDC) disk as an electrolyte. LSCN, LSCNP, a composite of LSCN and SDC, or a composite of LSCNP and SDC (LSCNP or LSCN:SDC $=60: 40 \mathrm{wt} \%$ ) was used as an anode and $\mathrm{Sm}_{0.5} \mathrm{Sr}_{0.5} \mathrm{CoO}_{3}$ was used as a cathode. Mixture of $\alpha$-terpinol (99\% Wako Pure Chemical Industries, Ltd.) and Ethyl Cellulose (Kanto Chemical Co., Inc.) (80:20 wt \%) was used as a binder. Electrodes were prepared by doctor blade method. The electrode was painted in the size of $3 \mathrm{~mm} \times 3 \mathrm{~mm}$. It was dried at $100^{\circ} \mathrm{C}$ for $10 \mathrm{~min}$, and was sintered at $1100^{\circ} \mathrm{C}$ for $4 \mathrm{~h}$ using an electric furnace (SUPER-BURN SL1415C, Motoyama Co., Ltd.). After that, the cathode was prepared in the same manner and was sintered at $1050^{\circ} \mathrm{C}$ for $4 \mathrm{~h}$. The performance of the anode was measured using hydrogen and then methane as fuel. After using methane as fuel, the cell was oxidized using oxygen, and the performance of the cell was measured using hydrogen again. In this manner, the effect of carbon deposition was investigated.

\section{Results and Discussion}

Figure 1 shows the XRD spectra of the LSCNP powder, as prepared, after the reduction treatment, and after the re-oxidation treatment. It can be seen that the pattern of the spectrum changed by reduction treatment and that it returned to the same spectrum by re-oxida- (a)

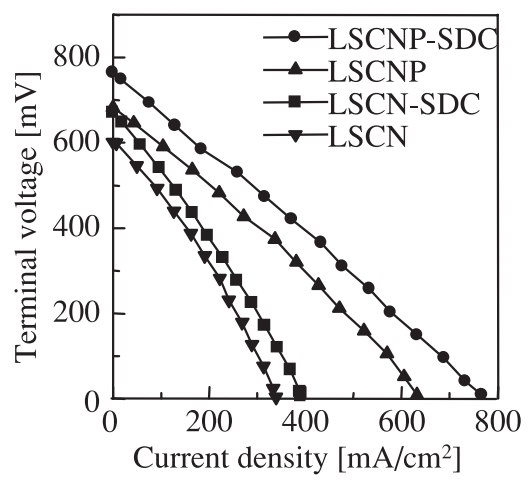

(b)

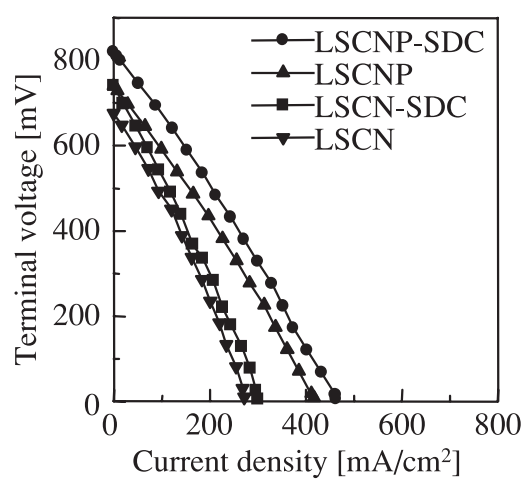

(c)

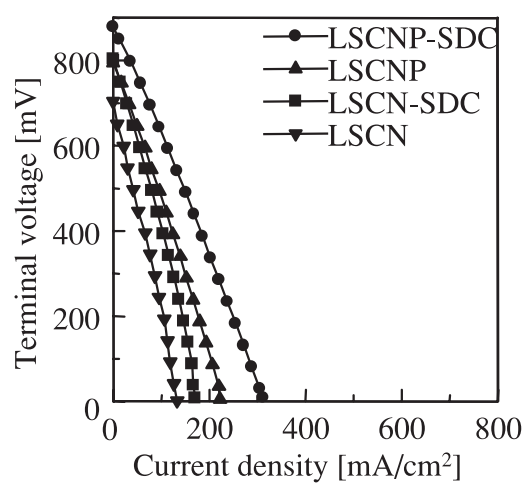

Fig. 2 Terminal voltage vs. current density of the cells with anode of LSCN and LSCNP with and without SDC using $\mathrm{H}_{2}$ as fuel at (a) 900 , (b) 800 , and (c) $700^{\circ} \mathrm{C}$

tion treatment, indicating the movement of Pd inside and outside the perovskite lattice due to the structural responses to the redox treatment.

Performance of SOFC cells with LSCNP, LSCNPSDC, LSCN and LSCN-SDC anode were measured. Figure 2 shows the terminal voltage vs. current density of the cells with each anode material using $\mathrm{H}_{2}$ as fuel at 900,800 and $700^{\circ} \mathrm{C}$, respectively. The maximum current density of LSCNP-SDC anode was the highest and was approximately $800 \mathrm{~mA} / \mathrm{cm}^{2}$ at $900^{\circ} \mathrm{C}$. Comparing the performance of LSCNP and LSCN, it can be seen that the addition of Pd enhanced the anode reaction. The maximum current density increased approximately twofold by the doping of $\mathrm{Pd}$ for the anode with or without SDC. Mixing SDC also had an 


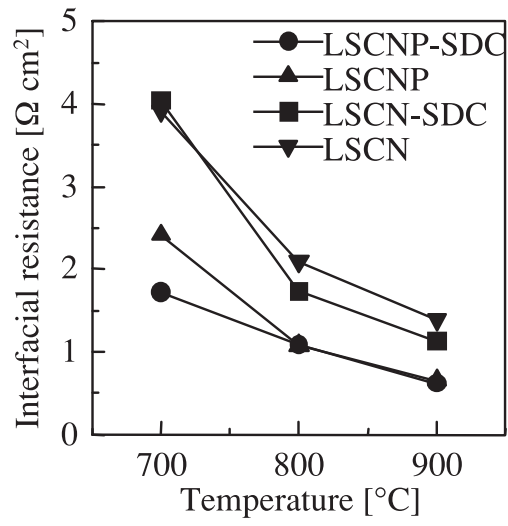

Fig. 3 Temperature dependence of the interfacial resistance of the cell for each anode material using $\mathrm{H}_{2}$ as fuel

enhancement effect on the performance. The rate of the anodic reaction in $\mathrm{H}_{2}$ was mainly determined by the catalytic activity of the perovskite, and was additionally enhanced by SDC.

Interfacial resistance of the anode for each material was calculated from the anode polarization, which is the voltage between the working electrode and the reference electrode. The slope of the anode polarization near OCV represented the interfacial resistance. Figure 3 shows the temperature dependence of the interfacial resistance of each anode. The slope of the interfacial resistance changed at $800^{\circ} \mathrm{C}$ except for LSCNP-SDC, indicating that the rate determining step of LSCNP-SDC is different from the other electrodes at $700^{\circ} \mathrm{C}$.

The cells were then operated using dry $\mathrm{CH}_{4}$ as fuel. In dry $\mathrm{CH}_{4}$, the cells showed lower performances compared to the cells operated in $\mathrm{H}_{2}$. For the cell with LSCN-SDC anode, the OCV was as low as $100 \mathrm{mV}$ at $900^{\circ} \mathrm{C}$, and was approximately zero at $700^{\circ} \mathrm{C}$. Moreover, the OCV of the cells with LSCNP and LSCN anode was approximately zero even at $900^{\circ} \mathrm{C}$. The cell with LSCNP-SDC anode showed OCV of ca. $700 \mathrm{mV}$, and was the only cell which was able to perform power generation test. Figure 4 shows the terminal voltage vs. current density of the cell with LSCNP-SDC anode at $900^{\circ} \mathrm{C}$ using dry- $\mathrm{CH}_{4}$ as fuel. The maximum current density was approximately $250 \mathrm{~mA} / \mathrm{cm}^{2}$ at $900^{\circ} \mathrm{C}$.

These results indicate that both the doping of Pd to the perovskite and the mixing of SDC contributes to the ability to operate $\mathrm{SOFC}$ in dry $\mathrm{CH}_{4}$. A schematic image of the reaction of each anode is shown in Figure 5. The supply of oxide ion was the rate determining step, since the anode reaction did not occur when SDC was not in the anode. Pd, which is considered to deposit from LSCNP in reducing atmosphere, seemed to be the reaction site of the electrochemical methane oxidation. For LSCN anode, the reaction rate of the

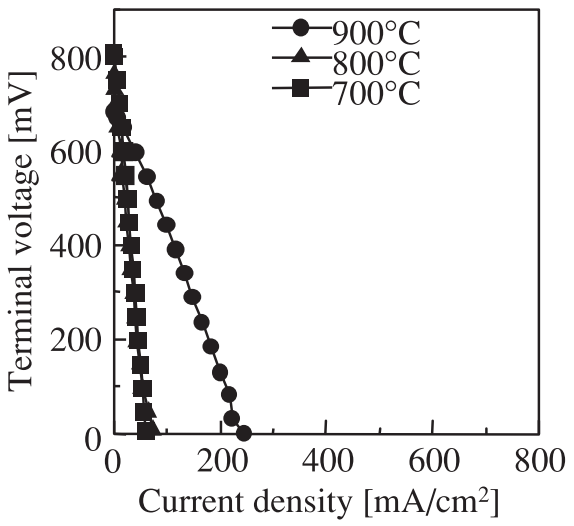

Fig. 4 Terminal voltage vs. current density of the cell with LSCNP-SDC anode using $\mathrm{CH}_{4}$ as fuel at various temperature

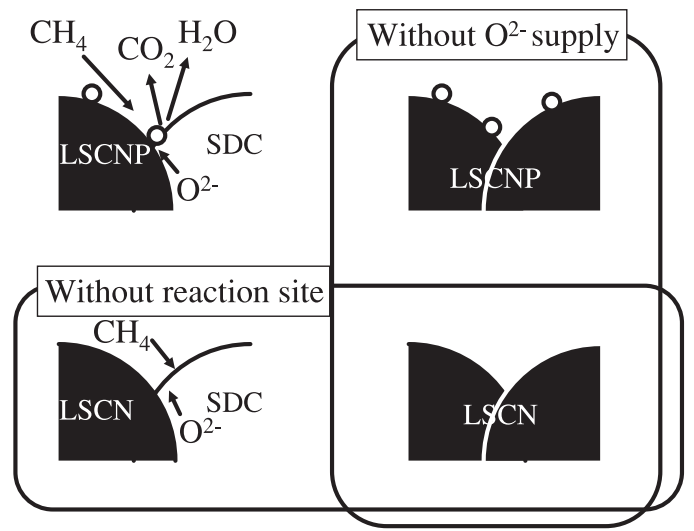

Fig. 5 Schematic image of the anodic reaction of LSCN and LSCNP with and without SDC

anodic reaction was low even when SDC was mixed in the anode, presumably since there was no reaction site. It had been reported by Sauvet and Irvine (2004) that LSCN shows catalytic activity for methane steam reforming. However, in our study, LSCN did not show sufficient activity for anodic reaction in dry- $\mathrm{CH}_{4}$. Therefore, the rate determining step of the electrochemical oxidation of dry- $\mathrm{CH}_{4}$ is considered to be different with the reaction when steam exists in the anode atmosphere. LSCN did not exhibit catalytic activity for the initial oxidation reaction of dry- $\mathrm{CH}_{4}$. It was only when LSCNP was in the anode that the initial oxidation of $\mathrm{CH}_{4}$ occurred, and presumably the produced $\mathrm{H}_{2} \mathrm{O}$ enhanced the anodic reaction of $\mathrm{CH}_{4}$.

After using methane as fuel, the performance of the cell in $\mathrm{H}_{2}$ was measured again. Figure 6 shows the comparison of terminal voltage vs. current density of the cell with LSCNP-SDC anode in $\mathrm{H}_{2}$, before and after the operation in $\mathrm{CH}_{4}$. The change in the performance was negligible at 700 and $800^{\circ} \mathrm{C}$. However, a slight decrease was observed at $900^{\circ} \mathrm{C}$, indicating a 


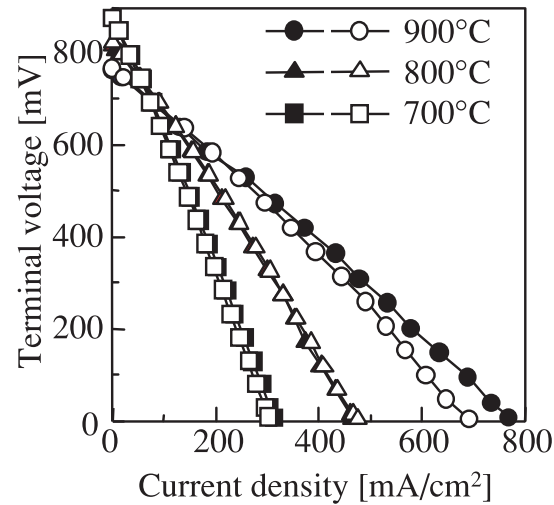

Fig. 6 Terminal voltage vs. current density of the cell with LSCNP-SDC anode in $\mathrm{H}_{2}$ at various temperature, before $(\bigcirc)$ and after $(\bigcirc)$ the operation in $\mathrm{CH}_{4}$

slight carbon deposition at high operating temperature. Further investigation in the rate determining step and the optimization of the electrode structure would make Pd doped perovskite a good candidate for metal-free SOFC anode.

\section{Conclusions}

A Pd doped perovskite LSCNP was investigated in comparison with LSCN as a metal-free anode material of solid oxide fuel cell. The performance of anodes of LSCNP and LSCN with and without mixing SDC was measured using $\mathrm{H}_{2}$ and dry- $\mathrm{CH}_{4}$ as fuel. The maximum current density of the cell in $\mathrm{H}_{2}$ increased approximately twofold by the doping of $\mathrm{Pd}$ for the anode with or without SDC. The rate of the anodic reaction in $\mathrm{H}_{2}$ was enhanced mainly by the catalytic activ- ity of the perovskite and additionally by SDC. When dry- $\mathrm{CH}_{4}$ was used as the fuel, the cell with LSCNPSDC anode was the only cell which was able to perform power generation. Both the doping of $\mathrm{Pd}$ to the perovskite and the mixing of SDC contributed to the ability to operate SOFC in dry $\mathrm{CH}_{4}$. The anode reaction did not occur when SDC was not in the anode, indicating that the supply of oxide ion was the rate determining step. Pd, which is considered to deposit from LSCNP in reducing atmosphere, seemed to be the reaction site of the electrochemical methane oxidation since the reaction rate was low for LSCN-SDC. Although slight indication of carbon deposition was observed, Pd doped perovskite would be a good candidate for metal-free SOFC anode.

\section{Acknowledgements}

This work was supported in part by a Grant-in-Aid for Young Scientists (B) of Ministry of Education, Culture, Sports, Science and Technology of Japan, No. 16760616.

\section{Literature Cited}

Nishihata, Y., J. Mizuki, T. Akao, H. Tanaka, M. Uenishi, M. Kimura, T. Okamoto and N. Hamada; "Self-Regeneration of a PdPerovskite Catalyst for Automotive Emissions Control," $\mathrm{Na}$ ture, 418, 164-167 (2002)

Pudmich, G., B. A. Boukamp, M. Gonzalez-Cuenca, W. Jungen, W. Zipprich and F. Tietz; "Chromite/Titanate Based Perovskites for Application as Anodes in Solid Oxide Fuel Cells," Solid State Ionics, 135, 433-438 (2000)

Sauvet, A. L. and J. T. S. Irvine; "Catalytic Activity for Steam Methane Reforming and Physical Characterisation of $\mathrm{La}_{1-x}$ $\mathrm{Sr}_{x} \mathrm{Cr}_{1-y} \mathrm{Ni}_{y} \mathrm{O}_{3-\delta}$," Solid State Ionics, 167, 1-8 (2004)

Sfeir, J., P. A. Buffat, P. Mockli, N. Xanthopoulos, R. Vasquez, H. J. Mathieu, J. Van Herle and K. R. Thampi; "Lanthanum Chromite Based Catalysts for Oxidation of Methane Directly on SOFC Anodes," J. Catal., 202, 229-244 (2001) 